\title{
Towards a Utilitarian Social Welfare Function-Income Inequality and National Welfare Growth in China
}

\author{
Songtao Wang ${ }^{1}, \mathrm{Bin}^{\mathrm{Li}}{ }^{1} \&$ Tristan Kenderdine ${ }^{2}$ \\ ${ }^{1}$ Business School, Shantou University, Shantou, China \\ ${ }^{2}$ Crawford School of Public Policy, Australian National University, Australia \\ Correspondence: Songtao Wang, Business School, Shantou University, 243 Da Xue Road, Shantou, Guangdong, \\ China. Tel:86-134-1191-6965. \\ Received: September 20, 2019 \\ Accepted: November 5, 2019 \\ Online Published: December 15, 2019 \\ doi:10.5430/rwe.v10n3p344 \\ URL: https://doi.org/10.5430/rwe.v10n3p344
}

The research is supported by "Shantou Science and Technology Plan Project (2016-116)".

\begin{abstract}
Since the beginning of the reform period, China's income inequality has increased. However, loss of national welfare and the impact of income inequality on the growth of national welfare has not been adequately assessed. The result is that any development model myopically focusing on efficiency and ignoring equality cannot maximize growth in national welfare. Grounded in utilitarian theory, this paper builds a national welfare function which incorporates the Gini coefficient and demonstrates the negative effects of income inequality on China's national welfare. We then provide a welfare-loss formula of income inequality and another formula to calculate the influence of income inequality change on national welfare growth. Our calculations show that from 1996 to 2010, the average welfare-loss rate of China's residents' income inequality was $8.08 \%$, with absolute welfare loss increasing 1.44 times; while the relative impact of Gini coefficient increases on national welfare growth was (-) 8.66\%.
\end{abstract}

Keywords: income inequality, Gini Coefficient, national welfare growth, utilitarianism; welfare economics

\section{Introduction}

Since the implementation of the reform and opening-up policy in the last century, China's economy has developed at a high speed, reaching an average annual rate of $9.5 \%$, and people's living standards have been greatly improved. At the same time, along with the rapid economic development, the income gap of China's residents has been expanding. From the Gini coefficient of 0.20 in 1980 to 0.4670 in 2017, China has entered a high level of income inequality.

Because the Chinese government and society have always focused on economic construction, paid too much attention to GDP growth, but not enough attention to income inequality. In fact, income distribution is as important as economic development. Income inequality will not only affect the macro aggregate demand, economic growth itself, but also national welfare and social development. Therefore, It has important practical significance to study the impact of income inequality on national welfare in China, and it is of great warning significance to improve the government's policy orientation.

Studies on the impact of income inequality on national welfare can be traced to welfare economics theory based on Bentham's (1957) and Mill's (1997) utilitarian political and economic philosophy. The 'law of diminishing marginal utility', developed by Ghosn (1997), Jevons (1984), Menger (1958) and Walras (1989), accepts that when total income is certain, the more unequal distribution, the lower the national welfare. Because there is no appropriate measure of income inequality, Pigou (2007) was unable to provide a strict proof. Dalton (1920) did provide a measure foran income inequality welfare-loss function, using a logarithmic utility function on the basis of utilitarianism and first proposed the concept of welfare-loss due to income inequality. Atkinsen (1970) was the first to combine a utilitarian social welfare function and the Lorenz curve, depicting income inequality to prove perfectly that when total income is certain, the lower part of the Lorenz curve(that is, the highest income inequality) demonstrates a lowering of the total social welfare. However, Dasgupta and Sen (1973) dispute this finding. They argue that the utilitarian social welfare function contains restrictive assumptions. These restrictive utilitarian assumptions have made economists seek alternative social welfare functions. 
Samuelson (1938) and Bergson (1947) proposed a general individualist social welfare function but they were unable to develop a concrete function. Therefore, as of 2016, we cannot accurately calculate social welfare. Common formulations of individualist social welfare functions contain elements of the neoclassical utilitarian social welfare function (Vickrey 1945), Nash's social welfare function (1950), Rawls' 'minimax' function (minimizing harm and maximizing good) (1971) and problems with weighting the role of elites in the social welfare function.

According to Sen, the individualist social welfare function involves the interpersonal comparability of utility (1974). However, Harsanyi (1955) and $\mathrm{Ng}$ (1984) find that when under conditions of weak assumptions, a social welfare function with interpersonal comparability must be the aggregate of non-weighted individual utility. Except for the utilitarian social welfare function, all other extant individualist social welfare functions ignore it.

In order to avoid interpersonal comparability and agglomeration of personal utility, welfare economists put forward the individualist social welfare function. Dasgupta\&Sen (1973) proposed a general form of symmetric and strictly quasi-concave individualist social welfare function, and proved the same proposition as Atkinsen (1970). The social welfare function meets most conditions of Arrow's impossibility theorem except that of ordinarily but it inevitably contains a cardinal utility assumption. While the symmetry assumption also contains the interpersonal comparability of individual utility, the same individual utility function and the same utility weight assumption which holds with individualism. There is no serious difference between the concavity assumption and the diminishing marginal utility assumption of the individual under utilitarianism, so the social welfare function does not take precedence over utilitarianism. Transforming Atkinson's index, Sen (1974) proposed a specific social welfare function now known as Sen's index:R=y (1-G). Sen's index meets both symmetry and concavity assumptions and contains both per capita income and a Gini coefficient. This index is simple and widely used in analysis of the national welfare and income equality. However, the index contains inherent contradictions. Foster(1997)used the Tell index and per capita income to build a social welfare function of individualism which faced similar problems to Sen's. Zhijun Zhao (2011) proposed a utilitarian individualist social welfare function comprising a society's lowest income, average per capita income and the Gini coefficient. However, the results are unsatisfying.

In general terms, analysis of the effect of income inequality on national welfare using utilitarian social welfare functions is preferable to other kinds of social welfare functions as the utilitarian method is both more reasonable and more functional. The basic assumption of utilitarianism is reliable and can be deduced by simple axioms. We explore five: utility cardinality, interpersonal comparisons of utility, diminishing marginal utility, social welfare as the sum of individual utility, and five?

\section{Five Utility Assumptions in Devising a Social Welfare Function}

A neoclassical utilitarian social welfare function must weight utility differently depending on the individual's ability to consume. $\mathrm{Ng}$ (1976) argues this breaks the Weak Majority Preference (WMP), making it difficult to observe each individual's ability to use a good in reality. Nash's social welfare function means that as long as there is an individual utility infinitesimal, the welfare of the whole society is an infinitesimal. This contradicts many basic principles, such as the Pareto criterion, WMP criterion, and accounting for governance institutions, for example authoritarian rule. Rawlsian social welfare functions to minimize and maximize utility haveal so been criticized for weighting the welfare of low-income earners too heavy (Harsanyi 1955). By contrast, elite social welfare functions too heavy weight efficiency, and ignore fairness, which results in unethical social inequality. Additionally, it violates the Weak Equity Axiom (WEA) or weak equal justice rules proposed by Sen (1974).

\subsection{The Utility Cardinality (Measurability) Assumption}

Utility cardinality is necessary to reasonably construct a function which can agglomerate individual utility into social welfare (Kemp \& Ng 1976, Park 1976). However, utility cardinality is still questioned by many economists (Pareto 1896, Slutsky 1915, Kolm1993) arguing that utility as a psychological form is immeasurable. Old welfare economics with cardinal utility at its core was replaced by new welfare economics after Hicks\&Allen (1932) introduced 'ordinal utility theory' and the 'no difference analysis' and Samuelson(1938) proposed a 'revealed preference theory'.

Although many economists believe that it is difficult to measure utility, this does not mean a rejection of cardinal utility. After Arrow (1951) proposed the 'impossibility theorem' of social choice, consensus coalesced around the idea that ordinal utility was an insufficient explanation. Arrow's social welfare function abandoned ordinarily and introduced a cardinal utility preference. Little (1952) and Samuelson (1967) have tried to overturn Arrow's impossibility theorem', but failed (Kemp \& Ng 1976, Park 1976). Sen (1970a) also put forward an impossibility theorem arguing that the 'ordinal doctrine' be abandoned. Based on limited discrimination sensitivity proposed by Borda (1781) and Edgeworth (1881), Ng (1975) gives a method for measuring utility. Clarke (1971) and Groves 
(1970) also put forward the revealed preferences mechanism in line with the incentive effect, which can also be used to measure utility. Aggregate social welfare functions therefore assume cardinal utility.

\subsection{Interpersonal Comparisons of Utility Assumption}

The interpersonal comparison of utility is necessary (Sen 1970a) for the social welfare function to aggregate individual utility into social welfare. Kolm (1993) argues interpersonal comparison of cardinal utility is impossible. However, $\mathrm{Ng}(1975,1982,1983,1996)$ argues individual cardinal utility is interpersonally comparable, and there are effective methods to compare this utility. If ordinal utility can be interpersonally compared, why can cardinal utility not be similarly compared? $\mathrm{Ng}$ (1984) concluded that in very general conditions, the interpersonal comparability of utility levels (ordinal utility) contains the interpersonal comparability of utility difference (cardinal utility). Therefore, to accept the interpersonal comparability of ordinal utility we should also assume the interpersonal comparability of cardinal utility.

\subsection{Diminishing Marginal Utility Assumption}

Since Ghosn (1997), Jevons (1984), Menger (1958) and Walras (1989) developed the concept of diminishing marginal utility, it has become the foundation of neoclassical economics. As a psychological law, it is almost certain. The law of diminishing marginal utility can actually be induced by the widely accepted Weber-Fechner law $(\mathrm{Ng}$, 1975). Even ordinal utility theory accepts the law of diminishing marginal utility. Ye Hang (2003) argues marginal utility theory is based on the assumption that utility can be directly measured (cardinal utility), which is actually a misunderstanding. The law of diminishing marginal rate of substitution in ordinal utility actually contains the diminishing marginal utility. If utility can be isolated and compared between different individuals, differences in the nature of utility can also be isolated and compared ( $\mathrm{Ng} \mathrm{1984).} \mathrm{As} \mathrm{a} \mathrm{result,} \mathrm{all} \mathrm{models} \mathrm{should} \mathrm{consistently} \mathrm{assume}$ diminishing marginal utility.

\subsection{Social Welfare as the Non-weighted Sum of Individual Utility Assumption}

Using the neutral observer assumption (an unseen, impartial observer), Harsanyi (1953, 1955), demonstrated that the cardinal social welfare function is probably the non-weighted sum of all social members' utility. Sen (1986) and Romer (1996) questioned the neutral observer assumption, but $\mathrm{Ng}$ (1984) argued that as long as the interpersonal comparability of utility is considered, Harsanyi's conclusion is reliable. Ng (1975) using the Weak Majority Preference criteria, also concluded that social welfare is the non-weighted sum of individual utility. Mueller (1989) argued the WMP assumption is too weak (weaker than either the Pareto criterion or majority rule), but that it is sufficient to support Bentham's utilitarian social welfare function.

\subsection{Similar Individual Utility Function Assumption}

The conclusion that the social welfare function is a non-weighted aggregate of individual utility implies individuals with the same hedonic ability (utility function) hypothesis, but Harsanyi (1953) and Ng (1984) did not directly illustrate this point. Sen criticizes utilitarianism (1976), and argues that the choice of utilitarianism deviates from the weak axiom. The weaker the hedonic ability, the more should be allocated. Weak equal justice based on equal utility as the goal, which adheres to the 'egalitarian', strictly concave social welfare function, obviously violates the Weak Majority Preference rule. Under the WMP hypothesis, as long as total utility is maximized, individual utility preferences are inconsequential ( $\mathrm{Ng} \mathrm{1984).} \mathrm{Besides,} \mathrm{it} \mathrm{is} \mathrm{difficult} \mathrm{to} \mathrm{effectively} \mathrm{identify} \mathrm{individuals'} \mathrm{differing}$ propensity to utilize a good. Lerner's (1944) research shows that even if different people have different propensities to utilize a good, given that the differing levels of propensity remain unknown, when total goods are aggregated, equal distribution can maximize total expected utility. Therefore, assuming that individuals have the same utility function or propensity to utilize a good, an aggregate social welfare function is feasible. In fact, the symmetry hypothesis in Sen's (1974) structure of an individualist social welfare function-Sen's index —also contains the same individual utility function assumptions.

\section{Theoretic Models}

According to the general analysis above and referring specifically to the research of Atkinsen (1970), Little \&Mirrlees (1974), Lord Layard \&Waltars (1994)and Dolan \& Tsuchiya (2009), this article uses the utilitarian social welfare function on the following basic hypotheses of utilitarianism: 1) utility cardinality (measurability); 2) interpersonal comparability of utility; 3) diminishing marginal utility; 4) differing individual utility function; 5) social welfare as the non-weighted aggregate of individual utility.

\subsection{Individual Utility Function and Diminishing Marginal Utility Applied to Individual Income}

Because consumption and wealth accumulation can reflect income utility, we will not apply the law of diminishing 
marginal utility to income directly. The following model uses a utility function which includes consumption and savings under the assumption of the diminishing marginal utility of both. The model then invites a conclusion of diminishing income utility. Because similar incomes of individuals offer differing utilities if the saving and consumption rates are different, our utility function is more realistic.

Firstly, we introduce the assumption of diminishing marginal utility for consumption. Set c for individual consumption and $\mathrm{U}(\mathrm{C})$ as the successive consumption utility function which satisfies:

$$
\text { (1) } \mathrm{u}(\mathrm{c}) \geq 0, \mathrm{u}^{\prime}(\mathrm{c})>0, \mathrm{u}^{\prime \prime}(\mathrm{c})<0 ; \lim _{\mathrm{c} \rightarrow 0} \mathrm{u}^{\prime}(\mathrm{c})=+\infty, \lim _{\mathrm{c} \rightarrow+\infty} \mathrm{u}^{\prime}(\mathrm{c})=0
$$

In general, the individual will not completely consume income, but rather save some as wealth. Wealth has three roles: 1) it brings the individual a sense of safety that deferred consumption liabilities can be met; 2) wealth opens the possibility of capital gain; 3) wealth has social effects such as fame, social status, self-worth etc. In other words, wealth itself brings utility to people. Some economists (Kuz 1968, Songtao Wang 2011) have already discussed bringing the concept of wealth as utility in to the utility function. Therefore, this article assumes at least some utility in wealth itself. Set $\mathrm{S}$ for individual savings (capital) and $\mathrm{U}(\mathrm{s})$ for the capital utility function which satisfies the assumption:

$$
\text { (2) } \mathrm{v}(\mathrm{s}) \geq 0, \mathrm{v}^{\prime}(\mathrm{s})>0, \mathrm{v}^{\prime \prime}(\mathrm{s})<0 ; \lim _{\mathrm{s} \rightarrow 0} \mathrm{v}^{\prime}(\mathrm{s})=+\infty, \lim _{\mathrm{s} \rightarrow+\infty} \mathrm{v}^{\prime}(\mathrm{s})=0
$$

Supposing the consumption and wealth utilities can be weighed, we getU $=u(c)+b v(s)$. Here $b>$ is the weight of wealth utility. Set incomey $=c+s$, thenU $=u(c)+b v(y-c)=U(c, y)$.

Using the above-mentioned assumptions, we can prove following proposition:

Proposition 1. When individual income utility increases, marginal utility decreases. Meaning $\partial U / \partial y>0$, $\partial^{2} U / \partial y^{2}<0$.

Proof: due to individuals making the best consumption decisions under the condition of the given $\mathrm{y}$, we have $\partial U / \partial c=0$, then: $\mathrm{u}^{\prime}(\mathrm{c})-\mathrm{bv}^{\prime}(\mathrm{y}-\mathrm{c})=0$

Denote $F(y, c)=u^{\prime}(c)-b v^{\prime}(y-c)=0$. Using the implicit function theorem, we get:

$\frac{\partial c}{\partial y}=-\frac{F_{y}(y, c)}{F_{c}(y, c)}=\frac{b v^{\prime \prime}(y-c)}{u^{\prime \prime}(c)+b v^{\prime \prime}(y-c)}$.

According to assumptions (1) and (2), we can get:

$0<\frac{\partial c}{\partial y}<1$, then: $\frac{\partial U}{\partial y}=u^{\prime}(c) \frac{\partial c}{\partial y}+b^{\prime}(y-c)\left(1-\frac{\partial c}{\partial y}\right)>0$.

$\frac{\partial^{2} U}{\partial y^{2}}=u^{\prime \prime}(\mathrm{c})\left(\frac{\partial \mathrm{c}}{\partial \mathrm{y}}\right)^{2}+\mathrm{bv}^{\prime \prime}(\mathrm{y}-\mathrm{c})\left(1-\frac{\partial c}{\partial y}\right)^{2}+\left[\mathrm{u}^{\prime}(\mathrm{c})-\mathrm{bv}^{\prime}(\mathrm{y}-\mathrm{c})\right] \frac{\partial^{2} c}{\partial y^{2}}<0$.

If we assume the consumer utility function is subject to the conventional relative risk aversion (CRRA): $u(c)=$

$\frac{\mathrm{c}^{1-\delta}}{1-\delta}, \mathrm{v}(\mathrm{s})=\frac{\mathrm{s}^{1-\beta}}{1-\beta}$.

$0<\delta, \beta<1$ is the parameter; $\delta$ is the relative risk aversion coefficient.

The utility function of the individual income then becomes:

$$
U(c, y)=\frac{c^{1-\delta}}{1-\delta}+b \frac{(y-c)^{1-\beta}}{1-\beta}
$$

In terms of $\mathrm{F}(\mathrm{y}, \mathrm{c})=c^{-\delta}-b(\mathrm{y}-c)^{-\beta}=0$ we can derive a micro consumption function: $c=f(y)$, and make a simple transformation: $y-c=b^{1 / \beta} c^{\delta / \beta}$. Taking the logarithm on both sides: $\operatorname{Ln}(y-c)=(1 / \beta) \operatorname{Ln}(b)+$ $(\delta / \beta) \operatorname{Ln}(c)$

Using the figures for income y and consumption $\mathrm{c}$ to make regression analysis, we can then estimate the value of $(1 / \beta) \operatorname{Ln}(b)$ and $\delta / \beta$. When the value of $\delta$ is fixed, we can calculate $\beta$ and $b$, and then calculate the individual income utility:

$$
U(y)=\frac{(f(y))^{1-\delta}}{1-\delta}+b \frac{(y-f(y))^{1-\beta}}{1-\beta}
$$


Solving the consumption function $c=f(y)$ is difficult, so we can estimate the real consumption function directly. Set the power function as $c=a y^{d}$ and then

$$
\operatorname{Ln}(c)=\operatorname{Ln}(a)+d \operatorname{Ln}(y)
$$

We also can use the income y and consumption c figure to estimate parameters a and $b$, so the individual utility function is:

$$
U(y)=\frac{\left(a y^{d}\right)^{1-\delta}}{1-\delta}+b \frac{\left(y-a y^{d}\right)^{1-\beta}}{1-\beta}
$$

\subsection{Income Inequality of Negative Welfare Effects: Theoretical Derivation}

We use the classic Lorenz curve and Gini coefficient to measure income inequality. The Lorenz curve was proposed by Lorenz (1905) to measure the national income distribution. It is a curve made by the accumulation percentage of the total population according to income arrangements from low to high and income percentages of the total revenue for the relevant part of the population. Gini (1912) defines the income distribution inequality index according to the Lorenz curve, namely the 'Gini coefficient'. The Gini coefficient has become the standard indicator to measure inequality of income distribution. The Gini coefficient calculation formula (Sarabia 1999) is $G=1-2 \int_{0}^{1} L(p) d p$.

$p \in[0,1]$ is the accumulation percentage of population according to income arranged from low to high. The range of $\mathrm{G}$ is $[0,1]$. $\mathrm{G}=0$ means completely equal distribution; $\mathrm{G}=1$ means completely unequal distribution. We can work out the Gini coefficient through estimating the Lorenz curve function.

Many studies estimate the Lorenz curve function, such as Basmannet et al. (1999) Ryu \& Slottje (1996), Sarabia et al. (1999), and Chotika \& Griffiths (2002). Sararbia (2008) offered seven formulae of Lorenz curve functions and Gini coefficients based on classical income distribution. The Lorenz curve of classic Pareto income distribution is the most commonly used curve. This Lorenz curve fits reality very well and is widely used. Zhijun Zhao's (2011) research also shows that when the utility function assumes conventional relative risk aversion and a Gini coefficient is given, the optimal income distribution is the Pareto distribution. Considering the above, we used the conventional relative risk aversion utility function, so we chose the Lorenz curve function based on the classical Pareto income distribution: $L(p)=1-(1-p)^{B}$.

$\mathrm{B}>0$ is parameter. The Gini coefficient is

$$
G=1-2 \int_{0}^{1} L(p) d p=1-2 \int_{0}^{1}\left[1-(1-p)^{B}\right] d p=(1-B) /(1+B)
$$

We can get the parameter: $B=(1-G) /(1+G)$.

Then we can get the Lorenz curve function using the Gini coefficient as the parameter: $L(p)=1-(1-p)^{\frac{1-G}{1+G}}$.

Set $\mathrm{Y}$ for gross national income and $\mathrm{N}$ for the national population and the lowest individual income ranked in $\mathrm{i}$ position is (Wang et al. 2012, Wang and \&Wu 2013)

$$
y_{i}=Y *\left[L\left(\frac{i}{N}\right)-L\left(\frac{i-1}{N}\right)\right]=Y\left[\left(1-\frac{i-1}{N}\right)^{\frac{1-G}{1+G}}-\left(1-\frac{i}{N}\right)^{\frac{1-G}{1+G}}\right]
$$

The gross national income utility (the national welfare) is

$$
W=\sum_{i}^{N} U\left(y_{i}\right)=\sum_{i=1}^{N} U\left(Y\left[\left(1-\frac{i-1}{N}\right)^{\frac{1-G}{1+G}}-\left(1-\frac{i}{N}\right)^{\frac{1-G}{1+G}}\right]\right)=W(\mathrm{Y}, \mathrm{G})
$$

We can use (4) to prove the following proposition:

Proposition 2. National welfare is the reduction function of the Gini coefficient $\partial W / \partial G<0$. In other words, the more income inequality, the lower the national welfare.

Proof: According to function (4), we get

$$
\frac{\partial W}{\partial G}=\frac{-2 Y}{(1+G)^{2}} \sum_{i=1}^{N} U^{\prime}\left(\mathrm{y}_{\mathrm{i}}\right)\left[\left(1-\frac{i-1}{N}\right)^{\frac{1-G}{1+G}} \log \left(1-\frac{i-1}{N}\right)-\left(1-\frac{i}{N}\right)^{\frac{1-G}{1+G}} \log \left(1-\frac{i}{N}\right)\right]
$$


Set all individual income from low to high for $0<y_{1}<\mathrm{y}_{2}<\cdots<\mathrm{y}_{\mathrm{N}}$, according to proposition 1 , we get $U^{\prime \prime}(y)<$ 0 , then

$$
U^{\prime}\left(\mathrm{y}_{1}\right)>U^{\prime}\left(\mathrm{y}_{2}\right)>\cdots>U^{\prime}\left(\mathrm{y}_{\mathrm{N}}\right)>0
$$

In series, we get

$$
\sum_{i=1}^{N}\left[\left(1-\frac{i-1}{N}\right)^{\frac{1-G}{1+G}} \log \left(1-\frac{i-1}{N}\right)-\left(1-\frac{i}{N}\right)^{\frac{1-G}{1+G}} \log \left(1-\frac{i}{N}\right)\right]=0
$$

Set $\varphi(x)=(1-x)^{a} \log (1-x), \quad 0 \leq x \leq 1,0<a<1$, Then:

$\varphi^{\prime}(\mathrm{x})=-(1-\mathrm{x})^{\mathrm{a}-1}(\operatorname{aLog}(1-\mathrm{x})+1)$.

When $\mathrm{x}=1-\mathrm{e}^{-1 / \mathrm{a}}, \varphi^{\prime}(\mathrm{x})=0$; when $\mathrm{x}<1-\mathrm{e}^{-1 / \mathrm{a}}, \varphi^{\prime}(\mathrm{x})<0$, it means $\varphi(\mathrm{x})$ is the decreasing function. When $\mathrm{x}>1-\mathrm{e}^{-1 / \mathrm{a}}, \varphi^{\prime}(\mathrm{x})>0$, it means $\varphi(\mathrm{x})$ is the increasing function.

Set $i_{0}=\left\lfloor N-N e^{-1 / a}\right\rfloor$, then $i_{0}<N-N e^{-1 / a}<i_{0}+1$, and then:

$$
\frac{i_{0}}{N}<1-e^{-1 / a}<\frac{i_{0}+1}{N}
$$

When $\mathrm{i} \leq i_{0}$, then $\left(1-\frac{i-1}{N}\right)^{\frac{1-G}{1+G}} \log \left(1-\frac{i-1}{N}\right)-\left(1-\frac{i}{N}\right)^{\frac{1-G}{1+G}} \log \left(1-\frac{i}{N}\right)>0$,

When $\mathrm{i}>i_{0}$, then $\left(1-\frac{i-1}{N}\right)^{\frac{1-G}{1+G}} \log \left(1-\frac{i-1}{N}\right)-\left(1-\frac{i}{N}\right)^{\frac{1-G}{1+G}} \log \left(1-\frac{i}{N}\right)<0$

Transposing equation (6), we get:

$$
\begin{aligned}
& \sum_{i=1}^{i_{0}}\left[\left(1-\frac{i-1}{N}\right)^{\frac{1-G}{1+G}} \log \left(1-\frac{i-1}{N}\right)-\left(1-\frac{i}{N}\right)^{\frac{1-G}{1+G}} \log \left(1-\frac{i}{N}\right)\right]=\sum_{i=i_{0}+1}^{N}\left[\left(1-\frac{i}{N}\right)^{\frac{1-G}{1+G}} \log \left(1-\frac{i}{N}\right)-(1-\right. \\
& \left.\left.\frac{i-1}{N}\right)^{\frac{1-G}{1+G}} \log \left(1-\frac{i-1}{N}\right)\right] .
\end{aligned}
$$

Each series on each side is greater than 0 . Each times the positive multiplier $U^{\prime}\left(\mathrm{y}_{\mathrm{i}}\right)$ respectively and incorporating equation (5) we can then get

$$
\begin{aligned}
& \sum_{i=1}^{i_{0}} U^{\prime}\left(\mathrm{y}_{\mathrm{i}}\right)\left[\left(1-\frac{i-1}{N}\right)^{\frac{1-G}{1+G}} \log \left(1-\frac{i-1}{N}\right)-\left(1-\frac{i}{N}\right)^{\frac{1-G}{1+G}} \log \left(1-\frac{i}{N}\right)\right]>\sum_{i=i_{0}+1}^{N} U^{\prime}\left(\mathrm{y}_{\mathrm{i}}\right)\left[\left(1-\frac{i}{N}\right)^{\frac{1-G}{1+G}} \log \left(1-\frac{i}{N}\right)-\right. \\
& \left.\left(1-\frac{i-1}{N}\right)^{\frac{1-G}{1+G}} \log \left(1-\frac{i-1}{N}\right)\right]
\end{aligned}
$$

Transposed, we get:

$$
\begin{aligned}
& \sum_{i=1}^{N}\left\{U^{\prime}\left(\mathrm{y}_{\mathrm{i}}\right)\left[\left(1-\frac{i-1}{N}\right)^{\frac{1-G}{1+G}} \log \left(1-\frac{i-1}{N}\right)-\left(1-\frac{i}{N}\right)^{\frac{1-G}{1+G}} \log \left(1-\frac{i}{N}\right)\right]\right\}>0, \text { so: } \\
& \frac{\partial C}{\partial G}=\frac{-2 Y}{(1+G)^{2}} \sum_{i=1}^{N}\left\{U^{\prime}\left(\mathrm{y}_{\mathrm{i}}\right)\left[\left(1-\frac{i-1}{N}\right)^{\frac{1-G}{1+G}} \log \left(1-\frac{i-1}{N}\right)-\left(1-\frac{i}{N}\right)^{\frac{1-G}{1+G}} \log \left(1-\frac{i}{N}\right)\right]\right\}<0
\end{aligned}
$$

That is, the greater income inequality, the lower the national welfare.

Proof of proposition 2 actually implies income $Y$ and distribution $G$ are independent of each other. That is to say, we discuss the influence of different distributions to the national welfare assuming the income is given.

The change of the Gini coefficient does not have restrictions on the transfer direction of income, which means the Gini coefficient changes are able to transfer income from high-income to low-income, and are conversely able to transfer income from low-income to high-income. The change in Gini coefficient is the result of various income transfers, which is more consistent with reality. Considering the specific distribution of income, the proof in this paper is more concise than Atkinsen (1970).

According to proposition 2, it is easy to get the following proposition:

Proposition 3: if Gross National Income is given, the distribution of absolute equality $(G=0)$ is the National Welfare maximization, and the absolute unequal distribution $(\mathrm{G}=1)$ is the national welfare minimization. 


\subsection{Measurement Method of Income Inequality (Change) Impact on National Welfare (Growth)}

Traditional neoclassical economic models are mainly based on the assumption of homogenous representative consumers. Therefore, it is difficult to reflect the heterogeneity of income Gini coefficient in the macro function. Research on income distribution in the literature (Gini coefficient) affecting macro indices is usually limited to econometric analysis (such as regression analysis), which imposes some limitations on the use of data and measurement mechanisms. In this paper, the national welfare function can directly measure the Gini coefficient and the impact of its changes on the national welfare.

According to equations (4) and (3), we can get the welfare loss of income inequality:

$$
T W=W(Y, 0)-W(Y, G)=N U\left(\frac{Y}{N}\right)-\sum_{i=1}^{N} U\left(Y\left[\left(1-\frac{i-1}{N}\right)^{\frac{1-G}{1+G}}-\left(1-\frac{i}{N}\right)^{\frac{1-G}{1+G}}\right]\right)
$$

It is obvious that $\partial \mathrm{TW} / \partial \mathrm{G}<0$, meaning national welfare will decrease with income inequality. We can further get the weight of national welfare loss due to income inequality.

We can also calculate the impact on national welfare caused by Gini coefficient changes through Equation (4).

$$
p T W=\left(\frac{T W}{W(Y, 0)}\right)=1-\sum_{i=1}^{N} U\left(Y\left[\left(1-\frac{i-1}{N}\right)^{\frac{1-G}{1+G}}-\left(1-\frac{i}{N}\right)^{\frac{1-G}{1+G}}\right]\right) /\left[N U\left(\frac{Y}{N}\right)\right]
$$

Do the difference to equation (4), we get

$$
\begin{aligned}
& \Delta W=\frac{1}{Y} \sum_{i=1}^{N}\left\{U^{\prime}\left(\mathrm{y}_{\mathrm{i}}\right) \mathrm{y}_{\mathrm{i}}\right\} \Delta Y-\frac{2 Y}{(1+G)^{2}} \sum_{i=1}^{N}\left\{U^{\prime \prime \prime \prime \prime \prime \prime \prime}\left(\mathrm{y}_{\mathrm{i}}\right)\left[\left(1-\frac{i-1}{N}\right)^{\frac{1-G}{1+G}} \log \left(1-\frac{i-1}{N}\right)-\left(1-\frac{i}{N}\right)^{\frac{1-G}{1+G}} \log \left(1-\frac{i}{N}\right)\right]\right\} \Delta G \\
& \mathrm{y}_{\mathrm{i}}=Y\left[\left(1-\frac{i-1}{N}\right)^{\frac{1-G}{1+G}}-\left(1-\frac{i}{N}\right)^{\frac{1-G}{1+G}}\right] .
\end{aligned}
$$

The first term on the right side is the impact on national welfare caused by national income changes $\left(\operatorname{signed}_{Y} \Delta Y\right)$ and the second term is the impact on national welfare caused by Gini coefficient changes ( $\operatorname{signed}_{\mathrm{G}} \Delta G$ ). The ratio of each term to $\Delta \mathrm{W}$ is the contribution of corresponding factors. Bringing the individual income utility function (3) to this function, we get

$$
\begin{gathered}
\Delta W=\frac{1}{Y} \sum_{i=1}^{N}\left[a^{1-\delta} d \mathrm{y}_{\mathrm{i}}^{d(1-\delta)}+b\left(\mathrm{y}_{\mathrm{i}}-a \mathrm{y}_{\mathrm{i}}^{d}\right)^{-\beta}\left(\mathrm{y}_{\mathrm{i}}-a \mathrm{dy}_{\mathrm{i}}^{d}\right)\right] \Delta Y-\frac{2 Y}{(1+G)^{2}} \sum_{i=1}^{N}\left\{\left[a^{1-\delta} d \mathrm{y}_{\mathrm{i}}^{d(1-\delta)-1}+b\left(\mathrm{y}_{\mathrm{i}}-\right.\right.\right. \\
\left.\left.\left.a \mathrm{y}_{\mathrm{i}}^{d}\right)^{-\beta}\left(1-a \mathrm{dy}_{\mathrm{i}}^{d-1}\right)\right]\left[\left(1-\frac{i-1}{N}\right)^{\frac{1-G}{1+G}} \log \left(1-\frac{i-1}{N}\right)-\left(1-\frac{i}{N}\right)^{\frac{1-G}{1+G}} \log \left(1-\frac{i}{N}\right)\right]\right\} \Delta G
\end{gathered}
$$

Let us move to the variable consumption function. Assume that the parameters of the consumption function change, but for simplicity that parameter $d$ remains unchanged, we then get:

$$
\begin{aligned}
\Delta W= & \sum_{i=1}^{N}\left\{\left[\left(a \mathrm{y}_{\mathrm{i}}^{d}\right)^{-\delta}-b\left(\mathrm{y}_{\mathrm{i}}-a \mathrm{y}_{\mathrm{i}}^{d}\right)^{-\beta}\right] \mathrm{y}_{\mathrm{i}}^{d}\right\} \Delta a+\frac{1}{Y} \sum_{i=1}^{N}\left[a^{1-\delta} d \mathrm{y}_{\mathrm{i}}^{d(1-\delta)}+b\left(\mathrm{y}_{\mathrm{i}}-a \mathrm{y}_{\mathrm{i}}^{d}\right)^{-\beta}\left(\mathrm{y}_{\mathrm{i}}-a \mathrm{dy}_{\mathrm{i}}^{d}\right)\right] \Delta Y \\
& -\frac{2 Y}{(1+G)^{2}} \sum_{i=1}^{N}\left\{[ a ^ { 1 - \delta } d \mathrm { y } _ { \mathrm { i } } ^ { d ( 1 - \delta ) - 1 } + b ( \mathrm { y } _ { \mathrm { i } } - a \mathrm { y } _ { \mathrm { i } } ^ { d } ) ^ { - \beta } ( 1 - a \mathrm { dy } _ { \mathrm { i } } ^ { d - 1 } ) ] \left[\left(1-\frac{i-1}{N}\right)^{\frac{1-G}{1+G}} \log \left(1-\frac{i-1}{N}\right)-(1-\right.\right. \\
& \left.\left.\left.\frac{i}{N}\right)^{\frac{1-G}{1+G}} \log \left(1-\frac{i}{N}\right)\right]\right\} \Delta G
\end{aligned}
$$

Because the assumption variable in the difference formula is very small, we ignore terms above second order during the difference formula derivation process. Therefore, we need to make sure that in application the variable rate is relatively small. In the empirical test we take years for the unit of time to calculate the change of the year, then make accumulative calculations year by year.

\section{Empirical Analysis}

We use provincial panel data from 1996-2010 (excluding Hong Kong, Macao, Taiwan and Tibet, a total of 30 provinces and municipalities) to carry out the parameter estimation. We use data from 1996-2010 for income inequality to calculate its effects on the growth of national welfare. 


\subsection{Parameter Estimation}

Firstly, we use equation (1) to estimate the parameters of residents' utility function. Residents' consumption function is estimated based on equation (2) considering two different situations, changed and unchanged $a$ (with time change).

Because the utility function parameters are certain, according to type (1), set the panel mixed regression model (model 1) as

$$
L N S A V E_{i t}=a_{0}+a_{1} L N C O N S_{i t}+\varepsilon_{i t}
$$

According to type (2), set the panel mixed regression model (model 2) as

$$
L N C O N S_{i t}=a_{0}+a_{1} L N I N C_{i t}+\varepsilon_{i t}
$$

According to type (2), set the variable intercept period effect panel regression model (model 3) as

$$
L N C O N S_{i t}=a_{0}+a_{1} L N I N C_{i t}+\gamma_{t}+\varepsilon_{i t}
$$

$\mathrm{i}$ represents province; $\mathrm{t}$ represents year. $\mathrm{LNSAVE}_{\mathrm{it}}$ says part of the income savings is attained by using per capita disposable income (net income) to reduce per capita consumer spending. $\mathrm{LNCONS}_{\mathrm{it}}$ is per capita disposable income (net income). $\gamma_{\mathrm{t}}$ is period effect. $\varepsilon_{\mathrm{it}}$ is the random error term.

\begin{tabular}{cccc}
\hline & Mode 11(LNSAVE) & Model 2(LNCONS) & Model 3(LNCONS) \\
\hline Constant term C & $-2.960312^{* * *}$ & $0.223325^{* * *}$ & $0.134445^{* *}$ \\
LNCONS & $(-13.43021)$ & $(4.724202)$ & $(2.174530)$ \\
LNINC & $1.215535^{* * *}$ & - & - \\
Adjustment R2 & $(45.44504)$ & $0.941433 * * *$ & $0.951890 * * *$ \\
F Statistics & - & $(169.6067)$ & 0.986123 \\
P & 2065.252 & 0.984631 & 2128.072 \\
Panel observation & 0.0000 & 28766.43 & 0.0000 \\
Model type & 450 & 0.0000 & 450 \\
Model method & Panel Least Squares & Panel Least Squares & Panel EGLS \\
\hline
\end{tabular}

Figure 1. Estimation and test results

Note: $\mathrm{t}$ shown in brackets is test value. $* * * * *$ means $5 \%, 10 \%$ significance level. Period effects in Model 3 are omitted.

\begin{tabular}{ccccccc}
\hline & $\begin{array}{c}\text { National } \\
\text { income Y } \\
\text { (hundred } \\
\text { million) }\end{array}$ & $\begin{array}{c}\text { Cities Gini } \\
\text { coefficient } \\
\text { Gr }\end{array}$ & $\begin{array}{c}\text { Countrysid } \\
\text { e Gini } \\
\text { coefficient } \\
\text { Gr }\end{array}$ & $\begin{array}{c}\text { Residents } \\
\text { Gini } \\
\text { coefficie } \\
\text { ntG }\end{array}$ & $\begin{array}{c}\text { Total } \\
\text { population N }\end{array}$ & Parameters $a_{\mathrm{t}}$ \\
\hline 1996 & 34439.30 & 0.2671 & 0.3229 & 0.3688 & $1,223,890,00$ & 1.199835 \\
1997 & 35911.52 & 0.2807 & 0.3285 & 0.3690 & $1,236,206,00$ & 1.169680 \\
1998 & 38992.87 & 0.2896 & 0.3369 & 0.3765 & $1,247,610,00$ & 1.133638 \\
1999 & 43265.91 & 0.2989 & 0.3361 & 0.3894 & $1,257,860,00$ & 1.115663 \\
2000 & 46161.70 & 0.3125 & 0.3536 & 0.4073 & $1,267,430,00$ & 1.153130 \\
\hline
\end{tabular}




\begin{tabular}{|c|c|c|c|c|c|c|}
\hline & & & & & 0 & \\
\hline 2001 & 50121.32 & 0.3259 & 0.3603 & 0.4197 & $\begin{array}{c}1,276,270,00 \\
0\end{array}$ & 1.136052 \\
\hline 2002 & 57077.52 & 0.3861 & 0.3646 & 0.4501 & $\begin{array}{c}1,284,530,00 \\
0\end{array}$ & 1.149454 \\
\hline 2003 & 61952.45 & 0.3973 & 0.368 & 0.4615 & $\begin{array}{c}1,292,270,00 \\
0\end{array}$ & 1.141497 \\
\hline 2004 & 65257.84 & 0.4057 & 0.3692 & 0.4627 & $\begin{array}{c}1,299,880,00 \\
0\end{array}$ & 1.139592 \\
\hline 2005 & 71443.98 & 0.4116 & 0.3751 & 0.4663 & $\begin{array}{c}1,307,560,00 \\
0\end{array}$ & 1.160536 \\
\hline 2006 & 78958.29 & 0.4078 & 0.3737 & 0.4681 & $\begin{array}{c}1,314,480,00 \\
0\end{array}$ & 1.149504 \\
\hline 2007 & 85852.90 & 0.4035 & 0.373 & 0.4691 & $\begin{array}{c}1,321,290,00 \\
0\end{array}$ & 1.137241 \\
\hline 2008 & 89268.87 & 0.4121 & 0.38 & 0.4718 & $\begin{array}{c}1,328,020,00 \\
0\end{array}$ & 1.124505 \\
\hline 2009 & 100358.87 & 0.4059 & 0.39 & 0.4713 & $\begin{array}{c}1,334,500,00 \\
0\end{array}$ & 1.133856 \\
\hline 2010 & 107802.33 & 0.3990 & 0.3847 & 0.4613 & $\begin{array}{c}1,340,910,00 \\
0\end{array}$ & 1.117126 \\
\hline
\end{tabular}

Figure 2. Parameters value from 1996 to 2010

Note: due to different data sources and calculation methods, the Gini coefficient in 2010, 0.458 in this paper, is slightly higher than the World Bank data.

We use 1996-2010 provincial panel data to estimate parameters, and adjust nominal data with a base price index (taking 1996 as base). Per capita data is obtained by weighting the proportion of urban and rural population based on per capita data of urban and rural residents. The source data is from historical provincial statistical yearbooks, calculated using EVIEWS6.0 software. Three models of F test results support the variable intercept model choice, and the Hausman test supports the fixed effects model. We use the generalized least squares method (EGLS) to manage the fixed effects model heteroscedasticity and serial correlation processing. The estimation results are in figure 1.

We can see that the estimated results of the three models are quite good. Model1 shows $\delta / \beta=1.215535$, $(1 / \beta) \operatorname{Ln}(b)=-2.960312$. Model 2 shows $\operatorname{Ln}(a)=0.223325$ (and thus $a=1.250227), d=0.941433$. Model 3 shows $\operatorname{Ln}\left(a_{t}\right)=0.134445+\gamma_{t}\left(a_{t}=1.143902 \mathrm{e}^{\gamma_{t}}\right.$, detailed data are shown in Figure 2$), d=0.951890$.

\subsection{The Welfare Loss Measurement of Income Inequality in China}

Equation (7) and (8) are used to calculate the welfare loss and the proportional loss caused by income inequality of residents in China. The individual income utility function is calculated by equation (3). The income utility function considers two different situations to the consumption function, 'constant' and 'variable' respectively.

There is relatively little empirical research of relative risk aversion coefficient setting, so the results demonstrate some problems. Layard et al. (2008) used a questionnaire survey about European and American countries to indicate that the value should be circa 1.26. Chen Xuebin (2005) in empirical research on Chinese residents' consumption saving behavior estimates that it should be around 0.77. Zelin Huang (2005) built an econometric model from the consumption behavior of residents to investigate the change rule of Chinese residents' consumption behavior and estimated $\delta=0.7$. Considering the different objects of study, we use the China scholar's estimates as they more closely fit our object. Firstly, set $\delta=0.7$. Combined with the above estimates, we can calculate $\beta=0.575878 ; B=0.181813$. When ignoring changes in the consumption function, the parameters $a=1.250227$, and $d=0.941433$. Considering changes in consumption function, parameters $\alpha$ is as shown in figure 2 and parameter $\mathrm{d}=0.951890$.

According to equation (7), besides parameters in the individual income utility function, we also need to know the gross national income $(\mathrm{Y})$, Gini coefficient $(\mathrm{G})$ and gross national population $(\mathrm{N})$. As for the gross national income in 
this article, we use the sum of urban residents' disposable income and rural residents' income, excluding government income. The Gini coefficient is calculated by the weighted method of urban and rural residents' Gini coefficient and per capita income of urban and rural residents (Zhou Yunbo 2009). The urban and rural residents' Gini coefficient comes from group revenue data calculated by the authors. Rural residents' Gini coefficient data comes directly from the National Bureau of Statistics. Raw data is from the China Statistical Yearbook. Nominal data is adjusted by using fixed Base Price Index (for the base period 1996). All index data are in figure 2.

According to (7) and (8), we use C++ language to program and Visual C++ 6.0 software to calculate. Results are shown in figure 3 .

\begin{tabular}{|c|c|c|c|c|c|c|c|c|c|c|}
\hline & \multicolumn{5}{|c|}{ Non-variable consumption function } & \multicolumn{3}{|c|}{ Variable consumption function } & \multirow[b]{2}{*}{$\begin{array}{l}\text { TW } \\
\left(10^{8}\right)\end{array}$} & \multirow[b]{2}{*}{$\begin{array}{l}\text { pTW } \\
(\%)\end{array}$} \\
\hline & $\begin{array}{c}\mathrm{W}(\mathrm{Y}, \mathrm{G}) \\
\left(10^{8}\right)\end{array}$ & $\begin{array}{l}\mathrm{pW} \\
(\%)\end{array}$ & $\begin{array}{c}\mathrm{W}(\mathrm{Y}, 0) \\
\left(10^{8}\right)\end{array}$ & $\begin{array}{l}\text { TW } \\
\left(10^{8}\right)\end{array}$ & $\begin{array}{l}\text { pTW } \\
(\%)\end{array}$ & $\begin{array}{c}\text { W. }(\mathrm{Y}, \mathrm{G}) \\
\left(10^{8}\right)\end{array}$ & $\begin{array}{l}\mathrm{pW} \\
(\%)\end{array}$ & $\begin{array}{c}\mathrm{W}(\mathrm{Y}, 0) \\
\left(10^{8}\right)\end{array}$ & & \\
\hline 1996 & 462.93 & 2.03 & 490.41 & 27.48 & 5.60 & 462.58 & 2.10 & 490.08 & 27.50 & 5.61 \\
\hline 1997 & 472.35 & 3.06 & 500.43 & 28.08 & 5.61 & 472.31 & 3.06 & 500.39 & 28.08 & 5.61 \\
\hline 1998 & 486.79 & 3.51 & 517.00 & 30.22 & 5.84 & 486.76 & 3.48 & 516.96 & 30.20 & 5.84 \\
\hline 1999 & 503.86 & 1.97 & 537.51 & 33.64 & 6.26 & 503.72 & 2.00 & 537.33 & 33.61 & 6.26 \\
\hline 2000 & 513.80 & 2.68 & 551.63 & 37.83 & 6.86 & 513.81 & 2.68 & 551.63 & 37.83 & 6.86 \\
\hline 2001 & 527.58 & 3.45 & 569.08 & 41.49 & 7.29 & 527.56 & 3.46 & 569.04 & 41.48 & 7.29 \\
\hline 2002 & 545.79 & 2.59 & 595.95 & 50.17 & 8.42 & 545.79 & 2.59 & 595.96 & 50.17 & 8.42 \\
\hline 2003 & 559.91 & 2.04 & 614.38 & 54.47 & 8.87 & 559.90 & 2.04 & 614.37 & 54.47 & 8.87 \\
\hline 2004 & 571.31 & 3.21 & 627.24 & 55.93 & 8.92 & 571.30 & 3.21 & 627.23 & 55.92 & 8.92 \\
\hline 2005 & 589.63 & 3.56 & 648.40 & 58.77 & 9.06 & 589.62 & 3.56 & 648.41 & 58.79 & 9.07 \\
\hline 2006 & 610.62 & 3.05 & 672.06 & 61.44 & 9.14 & 610.62 & 3.05 & 672.07 & 61.45 & 9.14 \\
\hline 2007 & 629.24 & 1.49 & 692.89 & 63.65 & 9.19 & 629.22 & 1.48 & 692.88 & 63.66 & 9.19 \\
\hline 2008 & 638.63 & 4.22 & 704.10 & 65.47 & 9.30 & 638.53 & 4.23 & 704.00 & 65.47 & 9.30 \\
\hline 2009 & 665.57 & 3.13 & 733.69 & 68.12 & 9.28 & 665.53 & 3.11 & 733.66 & 68.13 & 9.29 \\
\hline 2010 & 686.38 & 2.03 & 753.32 & 66.94 & 8.89 & 686.22 & 2.10 & 753.16 & 66.94 & 8.89 \\
\hline Average & 564.29 & 3.06 & 613.87 & 49.58 & 8.08 & 564.23 & 3.06 & 613.81 & 49.58 & 8.08 \\
\hline
\end{tabular}

Figure 3. Calendar year welfare growth and loss

Note: $\mathrm{pW}$ is actual growth of the national welfare $\mathrm{W}(\mathrm{Y}, \mathrm{G}) . \mathrm{W}(\mathrm{Y}, 0)$ means fully equal distribution of national welfare. TW means absolute welfare loss, pTW is welfare loss.

As we can see, using the non-variable consumption function and the variable consumption function have very little influence on the result, so we only analyze the non-variable consumption function.

The Gini coefficient 0.4718 in 2008 is the largest and the corresponding income inequality welfare loss rate is also the highest at $9.30 \%$. The smallest Gini coefficient is 0.3688 in 1996 and the corresponding income inequality welfare loss rate is also the lowest at $5.60 \%$; the average welfare loss rate of income inequality during the period of $1996-2010$ is $8.08 \%$.

The absolute loss of income inequality is $27.48 \times 108$ in 1996 and reached $66.94 \times 108$ in 2010. It is 2.44 times the 1996 level, which means it increased 1.44 times.

We can also see that the average growth rate of the national welfare in 1996 to 2010 is $3.06 \%$, which is far lower 
than the average income growth rate of $8.49 \%$ in the same period. The main reason is the diminishing marginal utility of income and residents' income inequality. The Gini coefficient, up from 0.3688 in 1996 to 0.4613 in 2010 is also an important factor. The specific influence on the national welfare growth caused by the expanding income gap will be addressed in the following section.

\subsection{Quantitative Analysis of Income Gap Change Influence on China's National Welfare Growth}

Above we calculated the real national welfare and its increase ratio and the loss ratio caused by income equality each year. The welfare loss caused by income equality is static data by year. Because the gross income and income equality change at the same time, each year welfare loss change cannot be the basis to calculate the influence that income equality change has on welfare. In terms of (9) and (10) difference equations, we can calculate the absolute and relative contribution of national welfare changes caused by Gini coefficient changes. The data comes from Figure 2 with further calculations on yearly variation. We used $\mathrm{C}++$ language to program and Visual $\mathrm{C}++6.0$ to calculate. The results are shown in figure 4.

\begin{tabular}{|c|c|c|c|c|c|c|c|c|c|}
\hline & \multicolumn{4}{|c|}{ Constant consumption function } & \multicolumn{5}{|c|}{ Inconstant consumption function } \\
\hline & $\left(10^{8}\right)$ & $\left(10^{8}\right)$ & $\begin{array}{l}\text { Total } \\
\left(10^{8}\right)\end{array}$ & $(\%)$ & $\left(10^{8}\right)$ & $\left(10^{8}\right)$ & $\left(10^{8}\right)$ & $\begin{array}{l}\text { Total } \\
\left(10^{8}\right)\end{array}$ & $(\%)$ \\
\hline 1996-1997 & 6.3291 & -0.0300 & 6.2991 & -0.48 & 0.4340 & 6.3291 & -0.0300 & 6.7330 & -0.45 \\
\hline 1997-1998 & 12.9663 & -1.1493 & 11.8170 & -9.73 & 0.1971 & 12.9663 & -1.1494 & 12.0140 & -9.57 \\
\hline 1998-1999 & 17.0751 & -2.0881 & 14.9869 & -13.93 & -0.0742 & 17.0708 & -2.0869 & 14.9097 & -14.00 \\
\hline $1999-2000$ & 10.8042 & -3.1275 & 7.6767 & -40.74 & 0.3275 & 10.8013 & -3.1247 & 8.0041 & -39.04 \\
\hline $2000-2001$ & 14.1279 & -2.3384 & 11.7895 & -19.83 & 0.0142 & 14.1279 & -2.3382 & 11.8039 & -19.81 \\
\hline 2001-2002 & 23.4911 & -6.1214 & 17.3697 & -35.24 & 0.0513 & 23.4841 & -6.1195 & 17.4159 & -35.14 \\
\hline $2002-2003$ & 14.9709 & -2.6096 & 12.3613 & -21.11 & -0.0019 & 14.9709 & -2.6095 & 12.3595 & -21.11 \\
\hline 2003-2004 & 9.5989 & -0.2919 & 9.3069 & -3.14 & -0.0048 & 9.5989 & -0.2919 & 9.3022 & -3.14 \\
\hline 2004-2005 & 17.4140 & -0.8972 & 16.5168 & -5.43 & 0.0647 & 17.4140 & -0.8971 & 16.5816 & -5.41 \\
\hline $2005-2006$ & 19.9580 & -0.4683 & 19.4897 & -2.40 & 0.0324 & 19.9580 & -0.4684 & 19.5220 & -2.40 \\
\hline 2006-2007 & 17.1745 & -0.2711 & 16.9034 & -1.60 & -0.0045 & 17.1745 & -0.2712 & 16.8989 & -1.60 \\
\hline $2007-2008$ & 8.0719 & -0.7571 & 7.3148 & -10.35 & -0.0510 & 8.0719 & -0.7571 & 7.2638 & -10.42 \\
\hline 2008-2009 & 25.5957 & 0.1435 & 25.7392 & 0.56 & 0.0721 & 25.5957 & 0.1435 & 25.8113 & 0.56 \\
\hline $2009-2010$ & 15.9439 & 2.9893 & 18.9331 & 15.79 & -0.0855 & 15.9439 & 2.9895 & 18.8479 & 15.86 \\
\hline 1996-2010 & 213.5214 & -17.0172 & 196.5043 & -8.66 & 0.9714 & 213.5073 & -17.0109 & 197.4678 & -8.61 \\
\hline
\end{tabular}

Figure 4. Influence on China's national welfare changes by year caused by Gini coefficient change

From figure 4 we can see that when the consumption function is constant, gross national welfare actually increased by $196.5043 \times 10^{8}$ from 1996-2010. However, the increased Gini coefficient resulted in a national welfare loss of $17.0172 \times 10^{8}$, which is $(-) 8.66 \%$ of the real national welfare change. When the consumption function changes, the effect of national welfare change caused by the Gini coefficient is relatively small at (-)8.61\%. The Gini coefficient increased each year from 1996 to 2008, resulting in a decline in the national welfare. The Gini coefficient increased from 1999 to 2000 to effect the national welfare changes, with the relative influence up to $40.74 \%$. The situation in 2009-2010 was reversed. In particular, in 2010 the effect that the Gini coefficient increase had relative to the national welfare change is up to $15.86 \%$. Obviously, residents' income gap in China does have a great influence on national welfare growth. In terms of economic growth, the implication is if we can narrow the income gap, there will be faster growth in national welfare.

\subsection{Sensitivity Analysis}

In the above calculation, we referred to estimates of other scholars and set the risk preference coefficient at 0.7. For sensitivity analysis to different risk preference coefficients, the value is $0.1 \sim 0.9$. Considering the result change with 
the consumption function change is small, we only conduct sensitivity analysis under the situation of a constant consumption function. The result is in figure 5 .

\begin{tabular}{|c|c|c|c|c|c|c|c|c|c|}
\hline \multicolumn{3}{|c|}{ Parameter value } & \multicolumn{4}{|c|}{ Income-inequality welfare loss calculation } & \multicolumn{3}{|c|}{$\begin{array}{l}\text { The national welfare change } \\
\text { decomposition }\end{array}$} \\
\hline & & $\mathrm{b}$ & $\begin{array}{c}\mathrm{W} \\
\left(10^{8}\right)\end{array}$ & $\begin{array}{l}\mathrm{W}(\mathrm{Y}, 0) \\
\left(10^{8}\right)\end{array}$ & $\begin{array}{l}\mathrm{TW} \\
\left(10^{8}\right)\end{array}$ & $\begin{array}{l}\text { pTW } \\
(\%)\end{array}$ & $\left(10^{8}\right)$ & Total $\left(10^{8}\right)$ & $(\%)$ \\
\hline 0.90 & 0.740415 & 0.111709 & 315.70 & 327.03 & 11.32 & 3.46 & -4.1177 & 39.3012 & -10.48 \\
\hline 0.80 & 0.658146 & 0.142513 & 368.27 & 238.08 & 23.81 & 6.07 & -8.4048 & 87.6259 & -9.59 \\
\hline 0.70 & 0.575878 & 0.181813 & 564.23 & 613.81 & 49.58 & 8.08 & -17.0172 & 196.5043 & -8.66 \\
\hline 0.60 & 0.493610 & 0.231949 & 969.11 & 1070.96 & 101.84 & 9.51 & -34.0470 & 443.540 & -7.68 \\
\hline 0.50 & 0.411342 & 0.295910 & 1778.13 & 1983.11 & 204.99 & 10.34 & -66.8925 & 1008.78 & -6.63 \\
\hline 0.40 & 0.329073 & 0.377510 & 3415.24 & 3814.92 & 399.68 & 10.48 & -127.635 & 2314.91 & -5.51 \\
\hline 0.30 & 0.246805 & 0.481611 & 6799.20 & 7537.59 & 738.38 & 9.80 & -231.426 & 5368.84 & -4.31 \\
\hline 0.20 & 0.164537 & 0.614418 & 13964.30 & 15192.31 & 1228.01 & 8.08 & -379.008 & 12613.2 & -3.00 \\
\hline 0.10 & 0.082268 & 0.783848 & 29543.06 & 31098.75 & 1555.69 & 5.00 & -474.518 & 30110.7 & -1.58 \\
\hline
\end{tabular}

Figure 5. Sensitivity analysis results

From figure 5 we can see that in the period of analysis the welfare loss rate is as high as $10.48 \%$. The welfare loss rate minimum is $3.46 \%$ and the welfare loss rate is $5.00 \%$. Thus as the parameter differs, the income-inequality welfare loss rate will differ. In general, the loss rate is a little high. The average is up to $7.87 \%$. It shows that the income-equality welfare loss does exist and cannot be ignored. Looking again at the composition of the national welfare change, the greater the value of $\delta$, the more negative impact on growth of national welfare is caused by income inequality. The relative effect rate is $-10.48 \%$. Considering the estimates of Layard et al., the negative influence that unequal growth has on national welfare will be greater.

\section{Conclusion}

Income inequality is widely agreed to negatively affect the aggregate national welfare. Since the beginning of the reform period in 1978, rising income inequality and economic growth in China has not maximized growth of the national welfare. Therefore, in order to promote coordination of economic growth and income equality and to maximize national welfare, we must evaluate the welfare loss and the influence on national welfare growth caused by the rise income inequality.

Existing literature has confirmed the feasibility of utilitarianism in the measure of national welfare. The main hypothesis of this article is based on the strict utilitarian proof on the negative welfare effect of income inequality. We provide an equation to calculate income inequality welfare-loss and the impact of change in income inequality on national welfare growth by building a national welfare function inclusive of income inequality using a Gini coefficient. The provincial panel data from 1996-2010 shows that the welfare-loss rate in China caused by income inequality is up to $8.08 \%$; that the welfare-loss in 2010 caused by income inequality was 1.44 times the 1996 level; and that the relative impact of Gini coefficient increases on national welfare growth was (-) $8.66 \%$. It is thus clear that current Chinese residents' income inequality should not be ignored in aggregate growth projections. The negative effects of income inequality on national welfare has already been relatively large.

Indeed, due to the existence of differences in individual incentives and ability, the authors do not completely agree with a purely equal distribution of income. However, if unfair income distribution or income inequality results in large-scale negative effects to the gross national welfare, it is certainly necessary to take measures to reduce income inequality. Otherwise, the legitimacy of economic growth will be completely undermined and its intended meaning and outcome - utility maximization - will be trapped in the paradox of growth.

\section{References}

Arrow, K.J. (1951). Social Choice and Individual Value. WHERE: Wiley Press. 
Atkinson, A.B. (1970). On the Measurement of Inequality. Journal of Economic Theory, 2(3), 244-263.

Basmann, R., Hayes, K., Johnson, J., \& Solottje, D. (1990). A general functional form for approximating the Lorenz curve. Journal of Econometrics, 43(1), 77-90.

Bergson, A. (1938). A Reformulation of Certain Aspects of Welfare Economics. Quarterly Journal of Economics, 52(2), 310-334.

Chen, X.B., Yang, L., \& Fang, S. (2005). Microeconomic Basis of Monetary Policy Effects: An Empirical Analysis of Chinese Residents' Consumption and Saving Behavior. Journal of Fudan Journal (Social Science Edition), 1, 42-54.

Chotika, P.D., \& Griffiiths, W.E. (2002). Estimating Lorenz Curves Using a Dirichlet Distribution. Business and Economic Statistics, 20(2), 290-95.

Clarke, E.H. (1971). Multipart Pricing of Public Goods. Public Choice, 11(1), 17-33.

Dalton, H. (1920). Measurement of the Inequality of Incomes. The Economic Journal, 30(119), 348-361.

Dasgupta, P., Sen, A.K., \& Starret, D. (1973). Notes on the Measurement of Inequality. Journal of Economic Theory, 6(2), 180-187.

deBorda, J.C. (1953). Mathematical Derivation of an Election System. (trans. De Grazia, A.) Isis, 44, 42-51.

Dolan, P., \& Tsuchiya, A. (2009). The Social Welfare Function and Individual Responsibility: Some Theoretical Issues and Empirical Evidence. Journal of Health Economics, 28(1), 210-220.

Edgeworth, F.Y. (1881). Mathematical Psychics. London: Kegan Paul.

Fang, F.Q., \& Lu, W.H. (2007). Evolution of a Social Welfare Function to see China's Equity Problem. Tianjin Social Sciences, 3, 69-74.

Foster, J.E., \& Sen, A.K. (1997). On Economic Inequality. Oxford: Oxford University Press.

Gini, C. (1912). Variabilità e Mutabilityà, Contributoallo Studio delleDistribución e RelazioniStatistiche. StudiEconomico -Giuridici dell' University di Cagliari.

Gossen, H.H. (1997). Development of the Law of Human Exchange and the Resulting Code of Human Behavior. Beijing: The Commercial Press.

Groves, T. (1970). The Allocation of Resources Under Uncertainty: The Informational and Incentive Roles of Prices and Demands in a Team' Ph.D. dissertation. University of California, Berkeley.

Harsanyi, J.C. (1953). Cardinal Utility in Welfare Economics and in the Theory of Risk-Taking. Journal of Political Economy, 61(5), 87-120.

Harsanyi, J.C. (1955). Cardinal Welfare, Individualistic Ethics, and Interpersonal Comparisons of Utility. Journal of Political Economy, 63(4), 309-321.

Harsanyi, J.C. (1975). Can the Maximin Principle Serve as a Basis for Morality? A Critique of John Rawls's Theory. American Political Science Review, 69(2), 594-606.

Hicks, J.R., \& Allen, R.G.D. (1934). A Reconsideration of the Theory of Value. Economica, 1(2), 196-219.

Jevons, W.S. (1984). A General Mathematical Theory of Political Economy. Beijing: The Commercial Press.

Kemp, M.C., \& Ng, Y.K. (1976). On the Existence of Social Welfare Functions Social Orderings and Social Decision Functions. Economica, 43(169), 59-66.

Kolm, S.C. (1993). The Impossibility of Utilitarianism. In Koslowsju, P., \& Shionoya, Y. (Eds.), The Good and The Economical: Ethical Choices in Economics and Management. Berlin and New York: Springer-Verlag.

Kurz, M. (1968). Optimal Economic Growth and Welfare Effects. International Economic Review, 9(3), 348-357.

Layard, R., \& Walters, A.A. (1994). Allowing for Income Distribution. In Laylard, R., \& Glasiter, S. (Eds.), Cost-Benefit Analysis (2nd ed.). Cambridge University Press.

Layard, R., Mayraz, G., \& Nickell S. (2008). The Marginal Utility of Income. Journal of Public Economics, 92(8-9), 1846-1857.

Lerner, A.P. (1944). The Economics of Control. New York: Macmillan.

Little, I. M.D. (1952). Social Choice and Individual Values. Journal of Political Economy, 60(5), 422-432. 
Little, I.M.D., \& Mirrlees, J.A. (1974). ProjectAppraisal and Planning for Developing Countries. London: Heinemann Educational Books.

Lorenz, M.O. (1905). Methods of Measuring the Concentration of Wealth. American Statistical Association, 9(70), 209-219.

Menger, C. (1958). Principles of National Economics. Shanghai: Shanghai People's Publishing House.

Mill, J.S. (1957). Utilitarianism. Shanghai: The Commercial Press.

Mueller, D.C. (1989). Public Choice II. Cambridge and New York: Cambridge University Press.

Nash, J.F. (1950). The Bargaining Problem. Econometrica, 18(2), 155-162.

Ng, Y.K. (1975). Bentham or Bergson? Finite Sensibility, Utility Functions, and Social Welfare Functions. Review of Economic Studies, 42(4), 545-569.

Ng, Y.K. (1982). The Necessity of Interpersonal Cardinal Utilities in Distributional Judgments and Social Choice. Zeitschriftfür National Ökomomie, 42, 207-233.

Ng, Y.K. (1983). Rents and Pecuniary Externalities in Cost-Benefit Analysis. American Economic Review, 73(5), 1163-1170.

Ng, Y.K. (1984). Interpersonal Level Comparability Implies Comparability of Utility Differences. Theory and Decision, 17(2), 141-147.

Ng, Y.K. (1990). Welfareism and Utilitarianism: a Rehabilitation. Utilitas, 2(2), 171-193.

Ng, Y.K. (1996). Happines Surveys: Some Comparability Issues and an Exploratory Survey Based on Just Perceivable Increments. Social Indicators Research, 38(1), 1-29.

Pareto, V. (1966). Coursd'EconomiePolitique. Lausanne: F. Rouge, 1896 (2 Vols.). In Pareto V. (Ed. S.E Finer) Sociological Writings (trans. D. Mirfin). Oxford: Basil Blackwell.

Park, R.P. (1976). An Impossible Theorem for Fixed Preferences: ADictatorial Bergson-Samuelson Welfare Function. Review of Economic Studies, 43(3), 447-450.

Pigou, A.C. (2007). The Economics of Welfare. Beijing: Huaxia Publishing House, China Press.

Rawls, J. (1971). A Theory of Justice. Cambridge, Mass.: Harvard University Press.

Romer, J.E. (1996). Theories of Distributive Justice. Cambridge, Mass.: Harvard University Press.

Ryu, H.K., \& Slottje, D.J. (1996). Two Flexible Functional Form Approaches for Approximating the Lorenz Curve. Journal of Econometrics, 72(1), 251-274.

Samuelson, P.A. (1938). A Note on the Pure Theory of Consumers' Behaviour. Economica, 5(17), 61-71.

Samuelson, P.A. (1947). Welfare Economics, Foundations of Economic Analysis. Cambridge, Mass.: Harvard University Press, pp. 203-253.

Samuelson, P.A. (1967). Arrow's Mathematical Politics. In Hook, S. (Ed.), Human Values and Economic Policy. New York: New York University Press.

Sarabia, J.M. (2008). 'Parametric Lorenz Curves: Models and Applications' and DuangkamonChotikapanich, 'Modeling Income Distributions and Lorenz Curves. Economic Studies in Inequality, Social Exclusion and Well-Being, 5(2), 167-190.

Sarabia, J.M., Castillo, E., \& Slottje, D.J. (1999). An Ordered Family of Lorenz Curves. Journal of Econometrics, 91(1), 43-60.

Sen, A.K. (1970a). Collective Choice and Social Welfare. San Francisco: Holden-Day.

Sen, A.K. (1970b). The Impossibility of a ParetianLiberal. Journal of Political Economy, 78(1), 152-157.

Sen, A.K. (1973). On Economic Inequality. Oxford: Oxford University Press.

Sen, A.K. (1974). Informational Bases of Alternative Welfare Approaches: Aggregation and Income Distribution. Journal of Public Economics, 3(4), 387-403.

Sen, A.K. (1976). Liberty, Unanimity, and Right. Economica, 43(171), 217-245.

Sen, A.K. (1986). Social Choice Theory. In Arrow, K.J., \&Intriligator, M.D. (Eds.), Handbook of Mathematical Economics (Vol.3, pp.1073-1181). Amsterdam: North Holland. 
Slutsky, E. (1925). On the Theory of the Budget of the Consumer (trans. O. Ragusa), GiornaledegliEconomisti, Vol. 51 July 1915 pp. 1-26. In G. J. Stigler \& K. E. Boulding (Eds.), Readings in Price Theory. Homewood Illinois: Irwin.

Veit, S. (2006). Neuroeconomics: Cardinal Utility in the Orbitofrontal Cortex?. Current Biology, 16(15), 519-593.

Vickrey, W. (1945). Measuring Marginal Utility by Reaction to Risk. Econometrica, 13(4), 319-333.

Walras, L. (1989). Elements of Pure Economics: or, The Theory of Social Wealth. Beijing: The Commercial Press.

Wang, S.T., \& Wu, C.L. (2013). Macroeconomic Effects of Income Inequality in China: Models, Methods and Data. Economic Review, 6, 34-43.

Wang, S.T., Wei, X.H., Tu, B., \& Yu, L.Z. (2012). Income Disparity and the Change of Labor Income in China - An Explanation of U-Shaped Development of GDP in China. Economic Science, 6, 33-47.

Wang, S.T., Yang, W., \& Wu, C. (2011). Construction and Estimation of the Chinese National General Utility Function. Statistical Research, 28(4), 17-23.

Ye, H. (2003). Logical Defects of Western Economic Utility Paradigms. Economic Research, 1, 93-97.

Zhao Z.J. (2011). Income Distribution and the Social Welfare Function. Quantitative and Technical Economic Research, 9, 33-47. 